(2) This book, No. 44 of the Oxford Pamphlets on World Affairs, is the second written by $\mathrm{Mr}$. E. Colston Shepherd upon matters aeronautical. The other, No. 28, was entitled "Britain's Air Power". These pamphlets are intended to be short, concise explanations of affairs that are necessarily the province of the specialist, written in such a manner that they appeal to the ordinary reader. This volume certainly maintains the high standard of these publica. tions and is well worth reading by those not familiar with the war developments in aviation. It is written in a restrained style, unclouded by the author's personal opinion too often, and presents the situation to-day, written by one who obviously knows much more than he thinks it politic to say in print.

The author explains the meaning and duties of the different types of war machines : the fighter, long-distance fighter, bomber, precision bomber, dive bomber, torpedo carrier, reconnaissance aircraft and army co-operation machine. He then discusses their possible developments and their limitations from the points of view of both their design and use. He finishes with a general discussion upon probable future developments, a dangerous procedure at any time, and particularly so when those developments take place under the stress of war-time demands. At least one of his prophecies has come true since it was written: "The Tornado fighter with its new Vulture Engine should have a speed of more than 400 m.p.h." His whole summing up is exemplified in one of his sentences, with which we must all agree, "Both sides are striving above all for more speed", and if he had added greater range or armament carrying capacity, he would have stated the case even more completely.

\title{
THE ULTRA-PERCEPTIVE FACULTY
}

\section{Exploring the U1tra-Perceptive Faculty}

By Dr. J. Hettinger. Pp. 172. (London: Rider and Co., 1941.) 12s. $6 d$. net.

IN this book Dr. Hettinger, whose previous work on the so-called ultra-perceptive faculty has already been noticed in NATURE (Feb. 22, p. 217), gives an account of further experiments in the same field, which he has devised partly in order to satisfy the need for a method of inquiry which, he thinks, may enable the faculty to be demonstrated at will.

For this purpose a person is first asked to set his watch at a time prearranged with another person or 'sensitive', who may be at any distance from him-in this case several miles. He is then asked to look slowly for about one hour at some illustrated periodical, reading any short articles that may be of interest and glancing at the illustrations, while noting down the times at which the various items were seen. At the other end the 'sensitive', in company with the experimenter, makes a series of statements which come into consciousness, the only link with the subject at a distance being some object or other belonging to the subject, this article being placed within reach or under the hands of the 'sensitive'. The experimenter then notes what is said by the 'sensitive', jotting down the times of the various statements at intervals of about one minute to correspond with the intervals noted by the subject when reading the periodical.

It is claimed that when the statements made by the 'sensitive' are compared with, for example, the illustrations seen by the subject, close approximation, both in time and subject-matter, is often established in a number of instances. Thus when the subject was looking at a photograph of a large horse, the 'sensitive' was saying, "Some admiration for large cart horses" ; and when the subject had a picture of a camera before him the 'sensitive' was saying, "A large camera and bright light". In both these cases and in many others no time lag is claimed, the times being almost, if not quite exact.

Although at first sight the results of these experiments may appear both striking and im. pressive, it would seem that Dr. Hettinger might have done better to delay publication until he had attempted a much closer and more detailed analysis of his results. In this report he has not printed a single one of the full statements of a 'sensitive' in any one case, a record clearly desir. able if the value of the items given is to be properly appraised. Moreover, Dr. Hettinger seems to have been somewhat too complacent when dealing with some of his results which, he thinks, can be accepted without applicable statistical checks and corroborative testimony by independent witnesses. How far he is right in this surmise remains to be seen. Suffice it to say that these findings are certainly of some interest; but it would seem that much work remains to be done and many control experiments devised, before it can be stated with any degree of confidence that here again we have solid evidence that some form of ultra-perceptive faculty has been fully established.
E. J. Dingwall. 